\title{
PRESIÓN SOCIAL PARA SER MADRE HACIA MUJERES ACADÉMICAS SIN HIJOS
}

\author{
Social pressure to be a mother toward \\ academic women without children
}

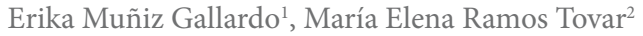

Fecha de recepción: 10 febrero de 2017

Fecha de aceptación: 24 abril de 2017

1- Nombre: Erika Muñiz Gallardo. Nacionalidad: Mexicana. Grado: Maestra. Especialización: Ciencias con Orientación en Trabajo Social. Adscripción: Universidad Autónoma de Nuevo León. Correo electrónico: erika.munizg@gmail.com

2- Nombre: María Elena Ramos Tovar. Nacionalidad: Mexicana. Grado: Doctorado. Especialización: Sociología. Adscripción: Universidad Autónoma de Nuevo León. Correo electrónico: maria.ramostv@uanl.edu.mx 


\section{Resumen}

Este artículo busca identificar los principales actores sociales que emiten la presión social para ser madre, las diversas formas lingüísticas que ésta adopta $y$ exponer dos estrategias de afrontamiento frente a dicha presión social desde una mirada analítica de género. El estudio es de corte cualitativo con una muestra intencional de cinco investigadoras de universidades públicas del norte del país. Entre los hallazgos que se muestran están, por un lado, que familiares, colegas en el trabajo, amistades e incluso personas desconocidas forman parte de los emisores de las demandas. Por otro se identifica que hubo quienes niegan explícitamente la presión, pero las narrativas exponen cómo dichas demandas son naturalizadas e incorporadas en su propio discurso. Finalmente se exponen las estrategias de afrontamiento más usadas por las entrevistadas: la confrontación y la re-significación.

Palabras clave: maternidad, mujeres sin hijos, académicas, presión social, estrategias de afrontamiento.

\section{Abstract}

This article identifies the main actors who express social pressure to be mother, as well as the different linguistic forms it takes, and it exposes two coping strategies used by academic women from a gender perspective. This study takes a qualitative approach with an intentional sample of five academic women from public universities in Northern Mexico. Some results suggest that there are diverse actors who pressure women to be mother such as family, colleagues at work, friends and even strange people. For some academic women, the feeling of pressure was denied, however, the narratives expose how such demands are naturalized and incorporated in their own discourse. Finally, confrontation and re-interpretation were the two main copping strategies used by those women.

Keywords: maternity, childless women, academics, social pressure, coping strategies. 


\section{Introducción}

C C.Por qué no tienes un hijo?” "De perdido ten un hijo!" "No estés sola" son parte de los mensajes que reciben las mujeres que no son madres como demandas para cumplir con las expectativas de género que son producto de una construcción cultural que asocia el ser mujer con el ser madre (Ávila, 2005). En éste trabajo, que forma parte de una investigación más amplia ${ }^{3}$, se expondrán las experiencias de mujeres investigadoras que, siendo mujeres sin hijos, no están exentas de la presión social para ser madres.

El artículo está organizado de la siguiente manera: dado que se parte de la noción de maternidad como construcción social, primero se expondrá ésta desde los diversos ángulos que ha sido analizada, para posteriormente y desde la perspectiva de género exponer lo que se ha dicho teóricamente de las mujeres sin hijos y la teoría del estrés y la emoción, que sirve de marco para comprender y analizar las estrategias de afrontamiento usadas por las entrevistadas. En un apartado siguiente, se describen algunos detalles metodológicos y por último se discuten los resultados obtenidos en la investigación y sus conclusiones.

\section{La construcción social de la maternidad}

Cuando de Beauvoir (1949) afirmó que "no se nace mujer: se llega a serlo" expuso el peso de la cultura en la ordenación simbólica de la diferencia sexual/genital, en el ser mujer, tanto en lo subjetivo como en lo colectivo. Es decir, que el ser mujer es producto de la ordenación de género y por lo tanto de la cultura. Del mismo modo, la maternidad es una cuestión de género y por lo tanto de la cultura que la ha interpretado un hecho "natural" y fenómeno clave en la identidad de las mujeres sean madres o no.

La noción de maternidad puede explicarse desde tres ángulos: el biológico, el sociocultural y el subjetivo. En su carácter biológico, la maternidad incluye el embarazo, el parto (Aguinaga, 2004; Asakura, 2000; Barrón, 2004) y la lactancia (Palomar, 2004). Sin embargo, en las culturas que "recurren a la coartada de un supuesto instinto maternal" (Aguinaga, 2004) el fenómeno de la maternidad posee un único significado que está alejado de su contexto histórico y cultural, adjudicando una característica permanente e invariable de lo femenino, a lo "natural" o lo biológico, lo que configura un imaginario que es a su vez "fuente y efecto del género" (Palomar, 2005).

Como construcción cultural, la maternidad incluye aspectos sociales, históricos e ideológicos lo que implica que existen normas que se desprenden de grupos sociales específicos en determinados momentos históricos que definen y organizan la noción de maternidad como construcción cultural (Palomar, 2005). Dichas normas a su vez, surgen de las representaciones socioculturales sobre la capacidad reproductiva de las mujeres y cumplen una función de control en cuanto a la sexualidad y fecundidad, lo que implica un conjunto de estrategias y prácticas discursivas que definen, construyen y limitan la feminidad, donde la mujer desaparece tras la función materna, la cual, queda configurada como su ideal (Tubert, 1996).

3- Este artículo es un extracto de la investigación de tesis de maestría que se titula: Mujeres académicas sin hijos: presiones sociales y estrategias de manejo. 
Por último, se encuentra la experiencia subjetiva que es entendida como la interpretación y reconstrucción del horizonte de significados y conocimientos que se producen dentro de contextos sociales y momentos históricos determinados (Lauretis, 1998) que también se entretejen a nivel inconsciente y por lo tanto del deseo (Ávila, 2005). En este sentido, Barrón (2004) señala que la maternidad implica una realidad experiencial dinámica (altamente significativa y constrictora), así como una construcción ideológico cultural que puede ser entendida de diversas maneras.

El elemento experiencial implica ver a la mujer no como víctima de la inercia social, sino como sujeta que tiene la posibilidad de construir y reconstruir sus deseos y experiencias a partir de los elementos socioculturales disponibles. Sin embargo, como menciona Tubert (1996) estas posibilidades se encuentran limitadas por dos aspectos: por un lado, un cuerpo orgánico y por otro, el haberse estructurado como tal en el contexto histórico de determinadas relaciones sociales, económicas y políticas que han construido su valor simbólico (es ahí donde se encuentra el elemento significativo y constrictor al que alude Barrón).

La noción de maternidad, por lo tanto, alude a lo biológico y es una construcción sociocultural que permea una diversidad de experiencias, motivo por el cual no puede hablarse de una representación única de la maternidad. Además, si bien la maternidad ha ido adquiriendo nuevos significados con el pasar del tiempo, en palabras de Díez (2000), ésta sigue siendo una metáfora organizadora de la sociedad y Fernández (2014) añade que es sumamente exigente además de inalcanzable ante las altas expectativas que se tiene de las madres (como la presión por ser una "buena madre").

Ahora bien, siendo que la maternidad es una construcción social creada dentro de una ideología patriarcal (Royo, 2004) se busca exponer cómo y por quiénes son presionadas las mujeres que no son madres para cumplir con este rol tradicional asignado a la mujer, además de las estrategias de afrontamiento usadas ante dicha presión. Para ello, la perspectiva de género permite analizar las posibilidades vitales de las mujeres y los hombres, el sentido que asignan a sus vidas, sus expectativas y oportunidades, las complejas y diversas relaciones sociales que se dan entre géneros, así como conflictos cotidianos (Lagarde, 1996).

\section{Ser mujer sin hijos}

Existen diversos motivos por los cuales algunas mujeres permanecen sin hijos y que han sido expuestos por diversas autoras. Por una parte está la falta de deseo de hijos y el rechazo de la maternidad (Ávila, 2005; Blackstone, 2014; Gillespie, 2000 y 2002; Hird y Abshoff, 2000), por otro lado está la elección ante los beneficios de no tenerlos (Gillespie, 2000 y 2002; Hird y Abshofff, 2000); los que llevaron a las mujeres a desistir de tener hijos y con lo cual se exhibe que se había intentado o bien, deseado (Ávila, 2004; Daver y Saugeres 2004; Hird y Abshofff, 2000); los factores que sólo explican la falta de hijos, mas no exponen una elección (Daver y Saugeres, 2004; Letherby, 2002; Shaw, 2011) y por último, los motivos involuntarios (Letherby, 1999).

Sin embargo, cualquiera que sea el motivo por el cual no tienen hijos, estas mujeres generan curiosidad, confrontación y señalamientos; son vistas como mujeres egoístas, ambiciosas o enmarcadas por la tragedia, lo cual expone que, en las dinámicas sociales cotidianas, no acaba de aceptarse el que las mujeres permanezcan sin hijos como una opción válida (Fernández, 2014). Así mismo, existen diversas 
estrategias que son usadas para llevar a las personas a ajustarse a las convenciones sociales, para hacer lo que se debe en determinados contextos, preocuparse por aspectos considerados esenciales en la vida o para generar interés en diversas circunstancias, lo que Lazarus (1999) denomina demandas sociales.

Dichas demandas, son definidas como presiones implícitas y explícitas del medio social que tienen la función de hacer actuar de determinada manera a las personas, así como mostrar actitudes que son apropiadas socialmente (Lazarus, 1999). Además, las demandas sociales son internalizadas por las personas, por lo que puede resultar complejo distinguir si son externas o internas (Lazarus, 1999) ya que esa interiorización no es un proceso que sea consciente.

Estas demandas sociales, al ser producto de una cultura de género, producen mandatos normativos y significados que son usados como medida común para delimitar la actuación de hombres y mujeres. Por ejemplo, Castellanos refirió que "la mujer mexicana, no se considera a sí misma -ni es considerada por los demás- como una mujer que haya alcanzado su realización si no ha sido fecunda en hijos, si no la ilumina el halo de la maternidad" (Castellanos, 1971: 289). En el mismo sentido, Lamas (2009: 112), expone que la función reproductiva de la mujer ha sido y sigue siendo todavía para grandes sectores de la población de nuestro país, lo que las vuelve valiosas, femeninas y "normales".

Si bien esta representación de la maternidad no es exclusiva de la sociedad mexicana, siendo ésta una cultura altamente influenciada por la religión católica, no es de extrañar que figuras como Eva y María sean símbolos de la mujer (Scott, 2011), o que la maternidad sea vista como un hecho natural, atemporal y universal (Palomar, 2005), o la mujer como recipiente de la voluntad divina (Lamas, 2009).

De esta manera se fomenta y exalta la maternidad y la dedicación de las mujeres a la vida de sus hijos y se transmiten generacionalmente como roles y expectativas que a su vez forman parte de una construcción tradicional de la así llamada feminidad. Oakley (1974) se da a la tarea de describir el mito de la maternidad moderna haciendo referencia a tres creencias que denomina falsas: 1 ) todas las mujeres desean ser madres; 2) todas las madres necesitan a sus hijos o hijas; 3 ) todos los hijos e hijas necesitan a sus madres.

Estos mandatos relativos a la maternidad se reproducen en diversos discursos e imágenes que suponen a las mujeres como sujetas que desean la maternidad y que es necesaria e inevitable para su desarrollo y satisfacción emocional, por lo que quienes no cumplen con estas expectativas o no sienten como propio o deseable ese ideal son consideradas “desviadas" o "deficientes" (Royo, 2011).

Los estereotipos, señalamientos y otras estrategias discursivas dirigidas hacia las mujeres sin hijos se expresan tanto en el discurso común de la sociedad, como por parte de opiniones "expertas" de los profesionales de la salud. En cuanto al discurso común, Ávila (2005) señala que la presión social puede apreciarse como comentarios o representaciones que se dirigen a conductas consideradas transgresoras del patrón cultural y coincide con Gillespie (2003) en que pueden encontrarse desde el lenguaje al no existir un concepto positivo para definir a las mujeres sin hijos y son descritas desde el prefijo adjetivado como "sin hijos" o "no madres". Como mencionan Abshoff e Hird (2000), las mujeres sin hijos son un oxímoron, definidas por lo que no son.

Esto implica una serie de supuestos producto de una interpretación cultural que se determinan por saberes que legitiman el sistema género, a partir del cual se percibe la realidad. Así, se produce un imaginario basado en características que definen a las mujeres y desde las que se desprenden estereotipos del ser mujer que incluso "ellas mismas se auto aplican" (Palomar, 2004). Es decir, al ser el sistema género 
una producción de la cultura y vía por la cual se percibe la realidad, las mujeres, al desarrollarse en estos sistemas culturales se apropian de las normas y tradiciones de los mismos.

Así, los estereotipos no sólo se reproducen hacia las mujeres sin hijos, sino también desde y hacia ellas mismas. Un ejemplo de ello es lo que señala Mamabolo, Langa y Kigwa (2007: 485) quienes mencionan que en Sudáfrica las mujeres sin hijos son percibidas como desviadas y posiblemente inmorales, es decir, son patlogizadas por desviarse de las expectativas de género impuestas, por lo que las mismas mujeres se convierten tanto para sí mismas como para otras, en una significativa "herramienta policial". Dicha "herramienta policial" consiste en que, desde discursos religiosos cuestionan la no maternidad o bien, manifiestan una incapacidad para comprender cómo alguien puede permanecer sin hijos.

Abshoff e Hird (2000) señalan que la maternidad es asociada con la madurez, lo que implica dos aspectos, por un lado, que las mujeres sin hijos no han alcanzado la adultez y por otro que la maternidad es reconocida como "etapa" del desarrollo psicosocial a través de la cual se confiere a la mujer la condición de adulto. Esto lleva a las opiniones "expertas", y es que los miembros de la comunidad médica siguen promoviendo el embarazo y el amamantamiento como curas para diversos malestares (como trastornos menstruales, ciertas formas de cáncer, etc.), y además persuaden a las mujeres infértiles para que dejen que sus cuerpos sean sometidos durante años a experimentaciones y pruebas médicas con la esperanza de tener un hijo (Daniluk, 1996).

También, desde la psicología tradicional, se encuentra la idea que sostiene que la maternidad es para las mujeres fuente de deseo natural y universal propio de un desarrollo psicosexual "normal" en el que la niña sustituye el deseo del pene por el deseo de un hijo (Badinter, 1981) y desde esta perspectiva la mujer sin hijos es un ser inadecuado psicológicamente, inmaduro y carente. Mannoni (1990) por su parte señala que la institución psicoanalítica ha producido con el significante maternidad el mismo efecto que la institución psiquiátrica con los diagnósticos, es decir, un abuso del poder basado en la perversión del saber, cuyas repercusiones se encuentran tanto en el pensamiento de los psicoanalistas como en las modalidades de trato, subjetivación y educación de las mujeres a partir de su capacidad reproductiva y ante la poca preocupación de algunas mujeres por ejercer la maternidad se les acusa de una identificación masculina o de la llamada envidia reprimida del pene.

En conclusión, tanto desde el discurso común de la sociedad como por parte de aquellos(as) expertos(as) del campo de la salud se imponen prejuicios culturales donde pueden encontrarse la idea generalizada que sostiene que la maternidad para las mujeres implica un deseo natural y universal que a su vez se manifiesta en un estado de maduración o bien, un estado de desarrollo psicosexual "normal" (Ávila, 2005).

Lo anterior hizo surgir la necesidad de conocer a mujeres que no sólo no cumplen con el ideal reproductivo asignado a sus cuerpos, sino que además, son mujeres que se tienen trabajos que se caracterizan por sus altas exigencias que consumen grandes cantidades de tiempo. En este mundo académico, del cual ellas forman parte, se identifican prácticas que promueven la ambición y la productividad y se cuestionan aquellas que lo impidan o que compitan con sus demandas de tiempo y dedicación, como es el caso de las demandas familiares (Acker, 1995; Halpern, 2007; Mason y Goulden, 2002; Williams y Ceci, 2012, entre otros). Así, se tuvo por objetivo, conocer si estas mujeres son cuestionadas por no tener hijos y si dichos cuestionamientos están asociados a su quehacer académico. 


\section{Método}

El estudio que se realizó es de corte cualitativo, no probabilístico, con una muestra intencionada final de cinco mujeres académicas reconocidas por el Sistema Nacional de Investigadores (SNI) del CONACYT que laboran en universidades públicas del norte del país, sin hijos con indistinta edad y estado civil.

\subsection{Participantes}

Dicho de manera general, las mujeres que conforman la muestra de investigación son mujeres con un alto nivel de estudios (doctorado y posdoctorado), algunos realizados fuera del país y que laboran en universidades públicas del norte de México. Sus edades oscilan entre los 32 y 50 años al momento de la entrevista, es decir, que entre ellas hay quienes aún se encuentran en su etapa reproductiva y quienes han culminado esta etapa. Así mismo, tienen indistinto estado civil, ya que tres de ellas son solteras y dos casadas. A continuación, se hace una breve descripción de cada una:

Raquel $^{4}$ tiene 47 años al momento de la entrevista, es casada (con un investigador, al igual que ella) y tiene cinco hermanos y hermanas, de los cuales, sólo uno tiene hijos, mientras que los demás, al igual que ella, han optado por no tenerlos. Sobre su condición de ser sin hijos, señala: "es un poco como: realmente vienes solo ¿no? Y entonces, no tienes quien te ayude, no tienes y es un poco por e... estoy todo el día aquí, realmente pues si no los voy a cuidar ¿para que los tengo? ¿No? realmente, es eso ¿no?”

Selene tiene 40 años al momento de la entrevista, es soltera y su familia está compuesta por sus padres y cuatro hermanos y hermanas. Tanto ella como uno de sus hermanos no tienen hijos. Respecto a ser sin hijos refiere: "cuando era muy chica si hubo un momento de veintitantos años que yo decía: "no yo no quiero tener hijos", y era como una determinación: "no quiero tener hijos", después y todavía en la maestría yo decía: "no quiero tener hijos", y después, y después, empecé a cambiar".

Aidé tiene 32 años al momento de la entrevista, es soltera y su familia está compuesta por su mamá, con quien vive y por una hermana casada y sin hijos. Su padre murió cuando Aidé tenía 10 años de edad. Sobre su condición de mujer sin hijos señala: "yo en ese momento hasta ahora yo he decidido, o sea apostar por una formación, y no, claro, no quito el dedo del renglón, ¿verdad? eso sí lo tengo muy claro”.

Rosa tiene 50 años al momento de la entrevista, es soltera y su familia está compuesta por sus padres y siete hermanos, éstos con hijos tanto propios como adoptados. Respecto a ser mujer sin hijos dice: "a lo mejor se va a escuchar muy egoísta pero, y bueno, 
la verdad es que sí lo es, eh este, veía sí, que como mamá tienes que modificar toda tu, tu vida, no sacrificarla, sino modificar porque ya es una persona, una persona que va a depender de ti por lo menos los primeros años y tienes que modificar tu estilo de vida, ya este, no eres tan libre para hacer lo que tú quieras, porque ya depende de ti una persona, no puedes viajar a donde tú quieras, en el momento que tú quieras, si y este, y bueno, pues a mí me, me, me gustaba no cambiar eso (risas) ¿sí?”

Carolina tiene 33 años al momento de la entrevista, ella está casada y planea tener hijos, aunque por ahora dice estar muy bien sin ellos. Acerca de su condición de ser sin hijos señala: "creo que como yo me proyectaba como investigadora, lo estoy cumpliendo muy pronto, o al menos así me visualizo de que digo: "yo no pensé a lo mejor a mi edad ya tener esto" ¿no? entonces, sé que, si lo hubiera planeado con otra forma, al momento, con hijos o... incluso ya ves que hay ciertos esposos un poco este (entre risa) aprehensivos y demás, yo digo: si yo hubiera tenido otro tipo de esposo, pues tampoco... a lo mejor no me hubieran dado esta libertad que tengo ahorita ¿no?"

\subsection{Procedimiento}

Para ubicar a las mujeres investigadoras sin hijos se utilizó la técnica "bola de nieve", dado que pertenecen a un subgrupo de la población difícil de identificar y los padrones accesibles no muestran información personal que pudiera usarse para seleccionarlas, al menos no con los criterios requeridos en la investigación. Este proceso inició con mujeres académicas cercanas, quienes proporcionaron datos de quienes cumplían (o posiblemente cumplían) con los requisitos antes planteados y también por recomendaciones dadas por algunas entrevistadas.

Por otro lado, también fueron seleccionadas a partir de la información publicada sobre mujeres académicas y las redes sociales. Por ejemplo, consulté entrevistas realizadas a mujeres académicas en internet y publicadas en libros que documentan logros e historias de vida de estas mujeres. En las entrevistas e historias de vida se encontró que algunas académicas revelaban información personal en la que mencionaban a sus hijos, lo que permitió hacer un filtro inicial para descartar aquellas que no cumplían con los criterios de selección, por lo que a las que no mencionaban este dato y fue posible localizar, se les invitó a participar; sin embargo, este método presentó algunas complicaciones. Al momento de realizar las entrevistas, se encontró que una de las mujeres seleccionadas para el estudio se encontraba embarazada y otra más, resultó tener una hija de 10 años. Así es que se decidió cotejar el listado obtenido con las redes sociales (de aquellas que contaban con una cuenta), por la información personal que se suele revelar en ellas.

Finalmente se localizaron y entrevistaron a diez mujeres académicas, de las cuales, sólo las entrevistas realizadas a cinco de ellas fueron usadas como parte de la muestra analizada. Los motivos por los cuales cinco entrevistas no fueron consideradas son debido a que, como se mencionó previamente, dos de ellas no reunían las condiciones de ser mujeres sin hijos, dos más no estuvieron disponibles para una segunda entrevista por motivos laborales y una más no respondió a la solicitud de un segundo encuentro. 


\subsection{Diseño del instrumento}

Se utilizó una guía, que sirvió de base para el desarrollo de la entrevista construida a partir de las categorías elaboradas en función de las preguntas de investigación. Son cinco los ejes centrales sobre los que se basa la guía de entrevista, de los cuales para el presente trabajo se considera la identificación de la presión social para ser madre y a sus emisores.

\subsection{Análisis de la información}

Para el análisis de la información se optó por el uso de la técnica de análisis del discurso con la finalidad de elaborar la interpretación de la información recuperada en las entrevistas, puesto que permite dar sentido y significado a aquello que las participantes expresaron durante las entrevistas tanto de manera explícita como lo que dijeron de manera no intencionada y que, sin embargo, están presentes en sus discursos. Sin embargo, esta técnica no permite que los datos lingüísticos hablen por sí mismos, por lo que para que tengan un significado, sentido y utilidad analítica se articulan con la teoría social.

De ésta técnica se retoman los marcadores del discurso, que son piezas lingüísticas que relacionan de manera explícita segmentos textuales, ya sean enunciados o secuencias de enunciados que consiguen establecer entre sí diversos tipos de relaciones semánticas y que pueden ser implícitos o explícitos (éstos modifican enunciados, organizan el texto y conectan sus elementos). También se hace uso de los conectores (tanto los marcadores como los conectores del discurso cumplen la función de "conectar", pero puede distinguirse entre ambos) que relacionan segmentos textuales que permiten establecer una relación semántica (ver Casamiglia y Tuson, 2001).

Así mismo, se analizan las estrategias de afrontamiento a partir de la teoría del estrés y la emoción de Richard Lazarus (1999). Las estrategias de afrontamiento (o manejo) son entendidas como recursos psicológicos que las personas ponen en marcha para hacer frente a situaciones estresantes. Sean o no exitosas, sirven para generar, evitar o disminuir conflictos (Macías, Madariaga, Valle, et al. 2013).

La propuesta de Lazarus (1999) propone un enfoque relacional del estudio del estrés y la emoción que centra su importancia en la relación entre la persona y el medio como una relación cuya particularidad radica en la emoción manifestada como parte de su manejo. Para que una situación sea considerada estresante por la persona, son necesarias condiciones que a su vez generan diferentes grados de estrés. Esto puede entenderse a partir de las variables personales (objetivos de la persona, creencias sobre sí mismos y el mundo, además de recursos como la inteligencia, el dinero, habilidades sociales, relaciones familiares y amistosas, etc.) y ambientales (demandas del medio, limitaciones impuestas, oportunidades presentadas y la cultura) que influyen sobre el estrés y la emoción (Lazarus, 1999).

Así, desde esta teoría, se produce una valoración del significado personal del encuentro, donde las variables personales y ambientales influyen en el estrés y la emoción además de moldear la valoración. Dicha valoración es entendida como la evaluación de las implicaciones de la situación (Lazarus, 1999), esto es: cómo puede afectarle o no, en relación a sus creencias y expectativas, además de las condiciones contextuales en las que la persona se encuentra inmersa. 
Se distinguen en la teoría dos tipos de valoración, la primaria y la secundaria. La valoración primaria implica la evaluación de si la situación es estresante o no. De no haber amenaza de estrés en el encuentro, no hay nada más qué evaluar en la situación, por otro lado, si se identifica la amenaza estresante, el estrés psicológico se presenta y es así que la valoración secundaria se presenta. Ésta se caracteriza por lo que hay qué hacer para manejar la situación estresante, lo que implica diversas posibilidades como asumir culpabilidad o crédito, actuar o no para reducir la amenaza, tener la expectativa de que la situación cambie sin acción personal que provoque dicho cambio, etc.

La valoración secundaria es la que permite que las personas modelen el manejo de la situación porque afecta el modo en que se entiende la naturaleza del encuentro adaptativo al que se enfrenta. En este sentido, la valoración es el sustrato cognitivo del afrontamiento. La eficacia del manejo depende del tipo de persona, del tipo de amenaza, del escenario o encuentro estresante y de la particularidad del resultado (bienestar que genera, funcionamiento social o salud somática subjetiva). Cabe destacar que la formulación del manejo como proceso es inherentemente contextual (Lazarus, 1999: 123).

Para Lazarus (1999), las dos funciones del manejo más importantes son la centrada en el problema y aquella que se centra en la emoción. La primera se caracteriza por la obtención de información para saber qué hacer y movilizar acciones con ese objetivo, o bien con acciones tendientes a ejercer un control en las relaciones con el medio. Por su parte, el manejo centrado en la emoción tiene la finalidad de regular las acciones producida por regular las emociones producidas por la situación estresante, por ejemplo, evitando pensar en la amenaza o re-significando la misma, sin modificar la realidad de la situación estresante.

En el presente trabajo se muestran dos estrategias de manejo usadas por las entrevistadas: la re-significación, que pertenece al tipo de estrategias centradas en el manejo centrado en la emoción y la confrontación, que corresponde a las centradas en la resolución del problema.

\section{Discusión de resultados}

Este apartado se divide en dos secciones, por un lado, se expondrán las narrativas en las que las entrevistadas señalan a quienes emiten los discursos identificados como presiones sociales para ser madre, para posteriormente, analizar los elementos lingüísticos que componen dichos discursos.

\section{1 ¿Quiénes presionan?}

Son diversas las demandas sociales dirigidas hacia las mujeres participantes en la investigación y que fueron identificadas. Se encontró que cuatro de las cinco entrevistadas dijeron sí haber percibido presión social para tener hijos, aunque de esas cuatro, tres hicieron énfasis en no sentir presión, aunque esa no fue la palabra usada para cuestionarlas (no obstante, el concepto de presión sí se llegó a usar en algunas preguntas, siempre, tras haber sido usado el concepto por las mismas entrevistadas).

Lo anterior puede deberse a que a todas se les solicitó su participación en una investigación para indagar las "presiones sociales dirigidas hacia las mujeres sin hijos y sus estrategias de manejo". Las preguntas que generaron las respuestas usadas en esta sección fueron dos: “¿qué expectativas tenía su familia de 
usted en tanto mujer?” y “ile han alentado a tener hijos?” o bien “ile han realizado comentarios por ser mujer sin hijos?” En la tabla 1 se muestran algunos extractos de las narrativas obtenidas en las que las entrevistadas describen algunas respuestas a éstas preguntas y en las que se expone quiénes emiten los discursos señalados como presión para tener hijos.

Tabla 1. Emisores de los discursos de presión identificados

\begin{tabular}{|c|c|}
\hline Emisores & Texto \\
\hline La familia & $\begin{array}{r}\text { [Mi mamá] a mí me presionó mucho [...] supongo que a mis hermanos también, yo creo } \\
\text { que para ella fue muy duro que decidiéramos, que decidiéramos que no. (Raquel) }\end{array}$ \\
\hline $\begin{array}{c}\text { Compañeros(as) de } \\
\text { trabajo }\end{array}$ & $\begin{array}{r}\text { [...] bueno, sí, aquí sí, fijate, qué chistoso, ¿no? Los más instruidos [...] algunos compa- } \\
\text { neros. Me hacen mis recomendaciones. (Selene) }\end{array}$ \\
\hline $\begin{array}{c}\text { Amigas y pareja } \\
\text { [...] y mis amigas, algunas amigas, no todas este, pero dos tres amigas (Carolina) }\end{array}$ \\
\hline $\begin{array}{c}\text { Otras personas } \\
\text { [...] le digo a mis amigas, al día de hoy, que la sociedad demanda (hace énfasis) en este } \\
\text { caso, pues, a la mujer trabajar y tener una familia [...] (Aidé) }\end{array}$ \\
\hline
\end{tabular}

Fuente: elaboración propia a partir de entrevistas a participantes.

En las entrevistas realizadas, distintos miembros de la familia y las personas con quienes se trabaja, fueron mencionados en mayor medida (en comparación con las amistades y otras personas) como quienes emiten discursos demandantes. En cuanto a compañeros y compañeras de trabajo, su alta frecuencia en la muestra puede explicarse debido a la cotidianidad de los encuentros con ellas y la familiaridad que esto produce.

Así, las otras personas (como las amistades, los psicólogos y la pareja) fueron mencionadas con menos frecuencia como quienes participan de estas demandas. Al ser éstas personas elegidas para mantener una relación cercana o bien, por ofrecer un servicio de salud representan una presión añadida, sin embargo, también existe la posibilidad de terminar estas relaciones (a diferencia de la familia o compañeros y compañeras de trabajo). Este es el caso de una de las entrevistadas (Rosa), quien mencionó haber concluido relaciones amorosas con motivo de la presión recibida por sus parejas para tener hijos, o el de Selene, cuya psicóloga "trataba de convencerla".

Entre quienes son señalados como emisores, destaca el hecho de que cuando se señalaron personas específicas (es decir, cuando no usaron el plural universal: todos, la sociedad, etc.) en su mayoría se refirieron a mujeres. Además, los ejemplos puntuales (como la mamá, la suegra, amigas, una señora en un avión, etc.), exponen que no necesariamente son personas cercanas a las mujeres entrevistadas quienes ejercen la presión, aunque sí lo son en mayor medida. 
Finalmente, también llama la atención que incluso personas desconocidas o sin una relación estrecha (construida por elección o impuesta) han intentado convencer a algunas de las entrevistadas de tener hijos, lo cual también representa un elemento importante de presión, ya que la coacción manifestada desde estas fuentes es producto del constante hacer género (Lorber, 1994), que es entendido como un proceso producto del género como condición social y que comprende las marcas de género y que son impuestas a partir de la asignación de sexo.

Dichas marcas implican el nombre, las ropas, accesorios y el comportamiento diferenciado, lo que permite a los individuos aprender (y transmitir) lo que se espera de ellos en tanto sujetos con género, lo cual es usado para diferenciar a los seres humanos en femenino y masculino (Lorber, 1994), a la vez que integra los procesos sociales y culturales de esta distinción de manera que actúan y reaccionan de acuerdo a estas expectativas. Esto, a su vez implica cuestionar aquellos comportamientos o bien, transgresiones al orden del género que, al llevarlos a cabo, legitiman y ayudan a construir y mantener dicho orden del género.

\subsubsection{La presión ¿ausente?}

Por otro lado, también se encontró quien señaló no recibir presión social para ser madre. En este sentido, Aidé, fue quien se destacó, y se señalan los fragmentos en los que niega la presión para ser madre:

No, yo creo que no, no sé si sea porque todavía me ven joven [...]

[...] no hay ninguna presión, para nada, sobre en qué momento voy a tener hijos

[...] nunca he recibido una sugerencia o algo, una presión en ese sentido, para nada, no.

[...] no es como que tenga una presión a ello [...]

[...] por ese lado [familiar], no, nunca, ninguna presión.

Los tres fragmentos centrales de estas respuestas de Aidé (es decir, descartando el primero y el último), corresponden a una misma respuesta, en la que negó reiteradamente la presencia de la presión, aunque como se expuso previamente, sí hace énfasis en las demandas de la sociedad. Cabe destacar que antes de comenzar la entrevista, Aidé realizó una aclaración: "nunca he recibido ningún tipo de presión", por lo que durante el encuentro, reafirmó que sobre la maternidad "nunca" ha recibido "presión" o "sugerencia".

Es importante también señalar la edad de Aidé, a lo cual hace alusión en su primera respuesta negativa (en ella, responde a la pregunta “ ¿de alguna manera le han alentado a tener hijos?"), ya que ella tiene al momento de la entrevista, 32 años, y en esa justificación expone tres situaciones: una de ellas es que, cuando dice: "no sé si sea porque todavía me ven joven" alude a cómo puede ser percibida por los demás y supone que es debido a esa percepción de juventud que no le han alentado a tener hijos, pero también que es la visión de los otros la de su juventud, más ella no se percibe, ni describe así en su respuesta. Por último, el hecho de que sea percepción de los otros la de una juventud a su vez muestra que el ser joven justifica el que no identifique la presión para ser madre.

Al igual que Aidé, quienes sí manifestaron explícitamente la presencia de demandas sociales, exponen que hay algunas personas de quienes no reciben estas demandas, o bien, muestran una contradicción al 
negar las demandas en sí. Es decir, la percepción de recibir o no presión varía y no siempre es reconocida. Sin embargo, convienen destacar dos aspectos para la presente investigación: por un lado, que el concepto de "presión" adquirió una connotación negativa para la mayoría de las entrevistadas, por lo que en ocasiones las entrevistadas usaron conceptos como "comentario", "aliento", "ánimo", ya que cuando se menciona el concepto de presión suele ser para negarla, aún y que se manifiesten en los ejemplos dados por ellas mismas y que pueden ser categorizados como tal.

Es en este sentido, que en el siguiente apartado se muestran dichos ejemplos y son identificados por los elementos lingüísticos que se destacan, identificación que responde a la técnica de análisis del discurso descrita previamente, usándose los conceptos de "presión” y "demanda" como sinónimos que los engloban. Dado que la presión social alude a las demandas del medio social que tienen la función de hacer actuar de determinada manera a las personas, así como mostrar actitudes que son apropiadas socialmente, estas condiciones son identificadas en el discurso, ya sea de manera implícita o explícita.

\subsection{Elementos lingüísticos usados como presión social para ser madre}

Yanina Ávila (2005) señala que una manera de documentar las presiones sociales para seguir la vía materna se puede encontrar en todos aquellos comentarios o representaciones que se dirigen a conductas consideradas como transgresoras del patrón cultural. Ahora bien, dichos comentarios o representaciones adquieren formas diversas en el discurso y son identificados como interrogaciones, sugerencias, persuasiones, manifestaciones de incredulidad, obligaciones, exhortaciones y el ejemplo, destacándose en cursiva y negritas los elementos lingüísticos que permitieron ésta categorización.

\subsubsection{Interrogaciones: “ipara cuándo tus hijos?”}

Las presiones fueron localizadas en múltiples manifestaciones de las entrevistadas y adquieren distintas formas, por ejemplo, como oraciones interrogativas. Estas son similares a las preguntas, pero se distinguen por que las preguntas buscan obtener información de la que se carece, mientras que las oraciones interrogativas tienen la propiedad de contener una incógnita y son expresiones "incompletas" y se distinguen en abiertas, parciales y disyuntivas (Bosque y Demonte, 2000). Nos ocuparemos por ahora de las oraciones interrogativas parciales que son las que se encontraron para esta categoría.

Una característica que posee este tipo de oración, es que la incógnita recae en el adverbio, pronombre o adjetivo usado:

Toda la gente ¿eh? Toda la gente, o sea desde, yo creo que desde que nos casamos, eh si, y o sea y... de alguna u otra manera y “cuándo van a tener hijos?” (Raquel)

En este ejemplo, la incógnita recae en el adverbio "cuándo", con lo que se busca saber en qué tiempo o en qué momento la cuestionada, tendrá hijos y quien la emite, parte de la certeza de que los hijos llegarán. 
- Revista de Ciencias Sociales y Humanidades. ISSN-P: 0188-9834 ISSN-E: 2395-8669.

También, hay otro tipo de interrogantes que por su contenido exponen que quien las emite hace una sugerencia o propone una alternativa.

\subsubsection{Sugerencias “¿por qué no adoptas?”}

Las sugerencias, según el diccionario, son insinuaciones, esto es, dar a entender algo sin más que indicarlo o apuntarlo ligeramente (Real Academia Española [RAE]). Estos corresponden a interrogativas disyuntivas y se caracterizan por restringir de manera expresa y por medios léxicos, las respuestas posibles (Bosque y Demonte, 2000: 3933) y en este sentido, hay una expresión indirecta de la exigencia:

[...] algunos compañeros si me han dicho así como que: “¿por qué no tienes un hijo?

O ¿por qué no adoptas?” (Selene)

Cuando una interrogación se refiere a una acción o comportamiento de su interlocutor y además se formula en negativo, se le cataloga como una sugerencia (Bosque y Demonte, 2000: 3942). Esto, aunado a que la segunda pregunta propone una alternativa. En otro ejemplo, se añade una concesión, es decir, una acción tendiente a ceder u otorgar algo (RAE):

Por ejemplo, mis hermanas que ya tienen hijos y de las cuales gozo los sobrinos, este, alentar en el... pero nunca a forzar ni nunca a presionar, sino: “ipor qué no tienes [hijos]? Aunque no te cases" (Rosa)

En ambos casos, se observan sugerencias realizadas con una interrogativa, esto forma parte de un fenómeno de cortesía donde quienes emiten las preguntas no se comprometen ni comprometen a sus interlocutoras, evitando así una demanda explícita. También puede observarse que se añade la concesión con lo que se acepta, real o aparentemente su convicción de no casarse (Rosa, durante la entrevista mencionó que su convicción es "no me voy a casar porque no quiero casarme").

Por otro lado, están las interrogaciones basadas en la convencionalidad, es decir, en el hecho de que la interlocutora conoce el contexto al cual se refiere quien enuncia las preguntas, por lo que no hay una referencia explícita al motivo que las provoca:

[...] sí hay ciertas amigas así que me dicen: “es que ¿cuándo vas a tener vida personal?" y para ellas tener vida personal es tener hijos. (Selene)

En este ejemplo no hay un contexto verbal precedente, pero es posible hacer una interpretación de la intención de la interrogación, ya que quien emite la interrogación no desea saber en qué momento ella tendrá una vida personal, puesto que "tener vida personal" es, como interpreta Selene, un sustituto de "tener hijos" con lo cual las emisoras evitan la demanda explícita. Por otro lado, esta demanda, surge de una crítica al tiempo de dedicación al trabajo que realiza Selene como investigadora, ya que para quienes la emiten, la vida personal y la vida laboral se perciben desligadas. 


\subsubsection{Persuasión: "tener hijos es lo máximo”}

Ésta se caracteriza por una manifestación de razones o argumentos cuya intención es convencer de hacer algo o pensar de cierta manera y se encontraron ejemplos en los que se exalta la maternidad:

[...] la otra es: "es la satisfacción más grande que puedes tener en la vida” ¿no? O sea, yo creo que son los argumentos que normalmente la gente utiliza (Raquel) [...] algunos compañeros si me han dicho así como que: "ay es que, es que tener los hijos, tener hijos es lo máximo" (Selene)

Estos fragmentos exhiben afirmaciones donde radica el componente persuasivo como argumento usado para convencer de lo que se afirma. El argumento, en los dos ejemplos, contiene un juicio de valor explícito de la maternidad, donde se generaliza y promete una satisfacción máxima atribuido al tener hijos.

Por otro lado, también hay ejemplos de persuasión donde se manifiesta la maternidad como un deber:

[...] una estudiante me dijo, ella es muy cristiana, me dijo: "Ay, debería de tener hijos, porque es importante y además las condiciones que usted tiene, podría enseñarle mucho" (Selene)

Y otro compañero de trabajo también me ha dicho así como: "pues debería de tener un hijo", que "eso es lo más bonito" (Selene)

En el primer ejemplo, el “debería” es usado para persuadir a Selene tener hijos, el motivo, se añade para aludir a sus facultades: "podría enseñarle mucho” manifestándose además en todos los ejemplos, el fenómeno de cortesía, ya que si bien el deber (expresado en los últimos ejemplos) manifiesta una obligación, se expresa de forma amable, con lo que se evita la demanda explícita.

\subsubsection{Manifestaciones de incredulidad: la descalificación.}

Dos de las entrevistadas expusieron ejemplos en los que revela la incredulidad respecto a su intención de permanecer sin hijos:

Y me decían: "no pues es que después vas a cambiar y vam..." [...] (Rosa)

[...] "no es que, no, no puede ser" [...] (Raquel)

En estos ejemplos se manifiesta la dificultad de creer en la opinión manifestada por las entrevistadas frente a su interlocutor, o bien, una descalificación de sus convicciones. Así se produce una reacción donde el argumento manifestado a Rosa apela a que sus convicciones cambiarán en el futuro en un intento de convencerla, mientras que en el de Raquel se expone únicamente la incredulidad del interlocutor frente a los motivos expuestos por ella. 


\subsubsection{La maternidad como obligación: "es que tienen que tener hijos"}

Las obligaciones se definen como imposiciones o exigencias que deben regir la voluntad libre y que sujeta a las personas a hacer o abstenerse de algo. Raquel muestra dos ejemplos de comentarios donde el tener hijos se expone como una obligación:

[...] “ies que tienen que tener [hijos]!”

Lo mismo de que: "no es que, no, no puede ser, tienen que pensar que cuando sean grandes alguien los tiene que cuidar" digamos eh, ese, como ese... esa tradición que a lo mejor es muy mexicana.

En estos ejemplos, la reacción que genera la decisión que Raquel refiere respecto a no tener hijos muestra sorpresa, en el primero, se expone únicamente la imposición "tienen que tener" de quien emite el mensaje, mientras que, en el segundo, expone además de incredulidad al inicio, la exhortación a pensar en los hijos como quienes tienen que cuidarlos cuando sean grandes, interpretado por Raquel como tradiciones mexicanas.

Llama la atención que en estos ejemplos se usa el plural "tienen", con lo cual Raquel expone que las demandas no son sólo de maternidad sino también de paternidad, es decir, esa demanda, se dirige a ella y a su esposo. Dichas demandas van más allá de la exigencia de cumplir un rol de género, ya que según la lógica de estas respuestas hay obligaciones, tanto para las parejas, como para los hijos que las parejas deben tener: tener hijos para que cuando los padres sean grandes, tengan quien los cuide.

\subsubsection{Exhortación a la maternidad: "ten un hijo para que no estes sola"}

Exhortar es la acción de incitar a alguien con palabras para que haga o deje de hacer algo. Se encontró un ejemplo en el que se revela el imperativo de la maternidad expuesto por parte de las hermanas de Rosa después de manifestar la sugerencia y concesión mencionadas previamente:

[...]me decían: "bueno, si no te quieres casar pues de perdido ten un hijo para que no estés sola" [...] (Rosa)

Cuando las hermanas de Rosa le dicen: "bueno, si no te quieres casar..." se exponen dos cosas: una es que hay una reacción de desacuerdo ante su convicción de no casarse y la segunda es que, ante esa reacción de desacuerdo, se expresa una condición, lo que se usa como argumento para dar una alternativa excluyente: "de perdido ten un hijo". Esta alternativa excluyente involucra una exhortación ante el incumplimiento de las expectativas.

Además, la parte final de este ejemplo determina el fin hacia el que se encamina la opción presentada y la motivación que la genera: que Rosa no esté sola. Este ejemplo, también, contiene formas distintas 
de expresar lo mismo: que se espera de Rosa que se case y tenga hijos. Pero como esa expectativa no se cumple (ante su convicción de no casarse y su negativa a tener hijos) se proporciona una alternativa esperando que al menos acepte el tener hijos. Esto expone expectativas de ellas en el círculo familiar: casarse y tener hijos.

\subsubsection{Las mujeres que son un ejemplo de vida.}

Un ejemplo, es una acción o conducta que se propone ya sea para que se imite y siga o bien para que se evite si es malo, y este se añade a las presiones para ser madre a pesar de que no corresponde a un discurso, puesto que Lazarus (1999) señala que presiones pueden ser implícitas o explícitas como producto del medio social que las genera con la intención de hacer actuar de determinada manera a las personas, así como mostrar actitudes que son apropiadas socialmente.

Aidé niega la presión para ser madre, sin embargo, señala que las demandas de familia y trabajo las produce la sociedad y a este comentario, añade lo siguiente:

[...] conozco a mujeres súper (hace énfasis) emprendedoras con familia, que hacen, no quita (hace énfasis) que sigan teniendo un trabajo directivo, por ejemplo, en empresas, que puede compatibilizarse, ¿verdad? con su familia, ¡sin descuidar! una familia preciosa, (hace énfasis) con unos hijos bien (hace énfasis) educados, que la verdad, la verdad que son ejemplo de vida ¿no?

El ejemplo de vida aludido por Aidé, expone que las mujeres "súper emprendedoras", que tienen un "trabajo directivo" pueden compatibilizar el emprendimiento y el trabajo con una familia, a la vez que no descuidan a los hijos y su educación. Cabe destacar que los ejemplos, son definidos como acciones o conductas que pueden inclinar a otros a que los imiten, por lo que Aidé, al señalar a estas mujeres como ejemplos de vida, alude a que son mujeres a imitar.

Así, en este caso, Aidé revela, por una parte, tal como menciona Díez (2000), el modelo actual de la maternidad, es decir, una exigencia social que incluye no sólo una familia ejemplar: una familia preciosa con unos hijos bien educados, sino también una trabajadora ejemplar: mujeres súper emprendedoras. Por otro lado, también revela la suma exigencia de las altas expectativas que se tiene de las madres. En este sentido, expone una imagen de mujer que sirve como espejo para que las mujeres se culpabilicen, se vean o imaginen en una condición altamente exigente que estructura la vida cotidiana.

En suma, son diversas las formas usadas para llevar a las mujeres sin hijos a ser madres, y en las narrativas expuestas se manifiestan muestras de discursos orientados a hacerlas planear su maternidad, o bien a resolver lo que es considerado una transgresión del patrón cultural. Así mismo, pude observarse una particular diferencia entre la categoría de persuasión, interrogaciones, sugerencias y el ejemplo donde las demandas adquieren un carácter implícito, mientras que en el resto de las categorías (exhortación, obligaciones, descalificación), éstas ya adquieren un carácter explícito.

Además, las narrativas expuestas, muestran que las demandas de maternidad no sólo provienen del exterior, sino que también son auto-dirigidas o bien dirigidas desde sí mismas hacia el exterior, y respec- 
to a este segundo caso es pertinente hacer una aclaración. Dado que el sistema género es producto de la cultura y la vía por la que se percibe la realidad (Palomar, 2004) se explica que las mujeres (habiéndose desarrollado en dicha cultura), se apropien y reproduzcan las normas y tradiciones de los mismos. Es en este sentido que también se explica que estos discursos no siempre sean reconocidos por las entrevistadas como estrategias para influir en sus decisiones reproductivas.

\subsection{Estrategias de afrontamiento}

¿Cómo afrontan las mujeres entrevistadas los discursos manifestados? Desde la perspectiva de Lazarus (1999), para que el afrontamiento tenga lugar es preciso que (en este caso) las mujeres valoren el encuentro demandante en función de sus implicaciones, esto es: si puede o no afectarle en relación a sus creencias y expectativas, además de considerar el contexto en el que dicho encuentro tiene lugar.

Como se mencionó previamente, el proceso de afrontamiento tiene dos funciones: una centrada en el manejo de las emociones y la otra en la resolución del problema, y una no es independiente de la otra (aunque cabe destacar que, para profundizar en su comprensión, en el presente trabajo se muestran ambas estrategias separadas). La primera función incluye la minimización, la evitación, tolerancia y aceptación de las condiciones estresantes, ya sea resignificando el estímulo o bien, mediante acciones, pensamientos, afectos y emociones (Macías, et al. 2013).

La estrategia centrada en la resolución del problema, por su parte, se caracteriza por intentos de ejercer un control en las relaciones con el medio, para lo cual, se requieren recursos. Dichos recursos se caracterizan por ser decisivos al momento de considerar las opciones de manejo para resolver las dificultades de la relación entre la persona y el medio (Folkman y Lazarus, 1984). Entre ellos están las creencias positivas de sí mismo, las habilidades para resolver problemas, las habilidades sociales, los recursos materiales y el apoyo social.

Así, frente a los eventos mencionados por las entrevistadas en los que se manifiesta alguna demanda para tener hijos, las principales formas de afrontamiento se concentran en la re-significación y la confrontación.

\subsubsection{Re-significación}

La re-significación como estrategia de manejo, comprende una modificación del significado asignado tanto a la amenaza como a las emociones, elaborando un nuevo significado relacional del encuentro estresante (Lazarus, 1999) y como se mencionó previamente, es uno de los modos más eficaces de manejarla, y no busca modificar la relación real persona-medio. Raquel, hace una distinción entre dos momentos en que se han presentado y cómo ha cambiado su manejo:

[...] al principio, yo creo que... o sea, por ejemplo, si, es como por ejemplo, intentar explicar por qué [...] pero, la gente realmente eh yo creo que cuando ya tienes una posición definida est, eh... es no siempre está abierta a escuchar los argumentos de 
otro [...] o sea es un poco, como intentar convencerlos con tus argumentos ¿no? $y$ después era, no pues "es que ya decidimos que no", "ah, no pues sî", "gracias", o sea digamos como que también vas evolucionando, vas aprendiendo las respuestas ¿no? [Risas] Como no engancharte, la, porque no son situaciones que uno quisiera discutir ¿no? O sea, tú ya decidiste y punto (Raquel)

Aquí ella explica dos distintas formas de manejar los encuentros estresantes de las demandas a partir de dos momentos. En el primer momento (aludiendo al inicio de su matrimonio) señala intentos de explicación de sus motivos (que parten de una posición definida) ante las demandas sociales, encontrándose con poca disposición de parte de los demás para escuchar sus argumentos. El segundo momento se caracteriza por respuestas aprendidas y desinterés en ahondar en sus respuestas a las preguntas, argumenta como motivo para ello el no "engancharse", y en ese sentido no quiere discutir y por lo tanto argumentar sus motivos.

Así mismo la re-significación expone que los encuentros, tal como eran afrontados en un principio favorecían una discusión de sus decisiones, situación indeseada en la medida en la que, ambas partes tenían una posición definida (tanto quienes demandan, como ella), por lo que después opta por el uso de respuestas aprendidas para no "engancharse" en dicha discusión. Así, se revela un fenómeno de cortesía donde Raquel no se compromete ni compromete a sus interlocutoras, evitando así adentrarse en una discusión Ella ha decidido (que no desea tener hijos) y punto.

También se encuentra la re-significación de demandas internalizadas. En este caso, tanto el apoyo social, como los recursos personales cumplen un papel relevante en la re-significación y Selene muestra un ejemplo en el que reflexiona acerca de la presión social para ser madre y cómo el apoyo de una psicóloga colaboró a dar un nuevo significado a las demandas:

[...] a veces si pienso: “y ¿cómo podría haber sido, o ser un hijo mío?” pero después me quedo pensando: "esas son tonterías", así como como... que tienen que ver con la cuestión de género, con la socialización y así con la eh, con cómo una va introyectando ciertas formas de ser mujer y la última psicóloga con la que estuve en tratamiento el año pasado [...] ella, me gustó mucho esta psicóloga porque es al contrario ella me decía: "ay, es que te oigo y oigo una señora antigua" o sea: "quítate eso de la mente" [...] yo le decía yo le decía: "es que yo me siento muy contenta pero cuando me empiezo a sentir así sufrimiento" es cuando, o le decía "[oigo E.M.] esas vocecillas sociales”, así: “¡es que no estás haciendo lo que... se supone que tendrías que hacer!” (Selene)

Este fragmento de Selene es muy revelador en la medida en la que expone la presión interiorizada y la resistencia a las manifestaciones de dicha interiorización, que denomina "tonterías" y asume como producto de las expectativas y normas de género introyectadas. Así, expone también cómo el sufrimiento sentido ante el estímulo de las "vocecillas sociales", por no hacer lo que se supone que tendría que hacer, es re-significado tanto por la reflexión del origen de dichas "vocecillas sociales", como por la exhortación a quitarse dichas ideas de la mente. 


\subsubsection{Confrontación}

La confrontación implica el encuentro de dos versiones contradictorias, donde lo significativo es que se trata de cambiar la postura del responsable del problema, o bien, hay expresiones de ira hacia quien lo causa (Lazarus, 1999). A diferencia de la re-significación, en la confrontación, se busca resolver la situación estresante frente a quien las provoca, por lo cual ésta estrategia se caracteriza por centrarse en la resolución de dicha situación entre la persona y el medio. Dos narrativas fueron identificadas con el uso de ésta estrategia de afrontamiento:

[...] mi convicción siempre fue: "yo no me voy a casar porque, pos no quiero casarme”, este, desde siempre ¿no? Entonces me decían: "bueno, si no te quieres casar pues de perdido ten un hijo para que no estés sola" y yo: "pobrecito ¿verdad?", les decía yo, les decía yo: "pues pobrecito el hijo que, que provenga de una madre que lo tenga nada más como compañía pues mejor te compras una mascota ¿no?” O sea, ¿qué karma le vas a dar a esa pobre criatura? (Rosa)

Como se había mencionado previamente, en la demanda expuesta por parte de las hermanas de Rosa, se manifiesta una reacción de desacuerdo ante su convicción de no casarse y una condición usada para exhortar al cumplimiento de perdido de una expectativa (de dos expuestas): tener hijos. En respuesta a ello, la reacción de Rosa exhibe las debilidades del motivo de la exhortación. Así, su respuesta adquiere un carácter sarcástico, en el que ridiculiza las pretensiones de su interlocutora. Esta ridiculización a su vez, forma parte de una reacción ante la injusticia identificada en el comentario: tener un hijo para no estar sola.

Además, se desliga del destino de su respuesta al no incluirse en el argumento que da cuando dice: “pues mejor te compras una mascota ¿no?”, ya que cambia a la persona señalada en el discurso y en lugar de responder desde la primera persona del singular (yo), responde en segunda persona, también cuando dice: “¿qué karma le vas a dar a esa pobre criatura?” exponiendo que las intenciones de compensación no son las suyas.

Carolina también manifestó una forma directa de manejo confrontador ante las presiones advertidas por parte de sus amigas, pero añade la exhortación manifestada de su parte ante la presión para tener hijos y describe como eso ha permitido que cese la presión:

[...] eso tengo un buen de tiempo que ya no [lo escucho E.M.], porque yo lo deje muy en claro ¿no? "El día que ya vean al bebé me dicen o que me vean embarazada ¿estás embarazada? Ah bueno, pero antes no me andes diciendo" ¿ ¿no? Yo eso lo dejé hace tiempo bien claro, y creo que todos lo entendieron bien, entonces, no ya, creo que ese tema como que ya quedó un poquito así, o sea no olvidado, pero está, así como reservado (Carolina) 
En este fragmento, Carolina manifiesta el motivo por el que ya no recibe cuestionamientos de sus amigas acerca de la llegada de los hijos, señalando que es porque ella dejó en claro su exhortación a que dejaran de hacer preguntas al respecto. Sin embargo, también añade una atenuación de los motivos (creo que ese tema como que ya quedó un poquito asî) y una aclaración (o sea, no olvidado, pero está así como reservado). Dicha aclaración se da en dos sentidos, por un lado, hacia las demandas (no asegura que esté olvidado el tema), y por otro lado, se exhibe que para ella misma tampoco, ya que ella señaló que quiere ser madre, ya sea por medio de un embarazo, o bien por adopción.

Ahora bien, estos casos donde la confrontación surge ante las demandas manifestadas por amigas y hermanas de las entrevistadas exponen una particularidad, que es la de la familiaridad, cercanía y confianza de las relaciones entre pares. En este sentido, los discursos que tienen la intención de que las entrevistadas desistan de sus convicciones (Rosa) o se imaginen en la condición de madres, facilitan una reacción confrontadora directa como sarcasmo (Rosa) y como exhortación (Carolina).

Cabe destacar que, si bien fueron cinco las entrevistadas para la investigación que da lugar al presente documento, no se exponen estrategias de afrontamiento para el caso de Aidé. Esto se explica en la medida en la que, como se señaló al inicio de este apartado, para que el manejo de la situación estresante tenga lugar, es preciso identificar en los encuentros donde la presión para ser madre tiene lugar como estresantes y dado que Aidé mencionó reiteradamente no recibir ningún tipo de presión en este sentido, tampoco manifestó situaciones como las mencionadas por el resto de las entrevistadas.

\section{Conclusiones}

Como se señaló en un inicio, este trabajo parte de una investigación más amplia donde se abordan las presiones sociales para ser madre y las estrategias de manejo que las mujeres investigadoras usan frente a dichas presiones y los aspectos mostrados en el presente trabajo, muestran una riqueza de información respecto a las diversas formas que adquiere la presión, así como de las diversas estrategias usadas por las mujeres entrevistadas para hacer frente a la misma.

Si bien algunas investigadoras entrevistadas manifestaron que no hay presión social para tratar de convencerlas de ser madre, lo cierto es que en las narrativas analizadas se observa que los discursos que pueden caracterizarse como presión social para ser madre adquieren diversas formas, donde, por un lado, se identifican aquellos que de manera explícita tienen la intención de coaccionar a quienes los dirigen, mientras que otros, son expresiones indirectas de la exigencia, y que al ser manifestados desde el reconocimiento del deber (de ser madre) y la certeza (de que éstas mujeres tendrán hijos), exhiben su intención de influir en las decisiones reproductivas de las mujeres.

En este sentido, vale señalar lo que Ávila (2005) señala respecto a que, si la maternidad fuera una vocación natural e instintiva, no harían falta los mecanismos de presión para "meter en cintura" a las mujeres que eligen no ser madres, sea de manera definitiva o bien, porque postergan el tener hijos.

Lagarde (1996) señala que desde un análisis antropológico de la cultura, es preciso reconocer que todas las culturas elaboran cosmovisiones sobre los géneros, por lo que cada sociedad, pueblo, grupo y todas las personas tienen una particular concepción del género basada en la de su propia cultura, en ese sentido, cada quien aprende a identificarse con la cosmovisión de género de su mundo y hasta hay quienes creen 
que la suya es universal. Esto permite entender el origen y la función que cumplen discursos como los señalados aquí, en la medida en la que parten de una imagen negativa (o de una incapacidad para concebir la imagen) de las mujeres que no son madres.

Así, dado que la perspectiva de género nos permite analizar y comprender las características que definen a las mujeres y hombres de manera específica, también permite analizar sus posibilidades vitales, el sentido otorgado a sus vidas, sus expectativas, oportunidades (Lagarde, 1996) y las formas de afrontamiento que, en el caso de la presente investigación, dan las entrevistadas a los discursos expuestos.

En cuanto a la relevancia de la muestra en tanto mujeres académicas, no se logró identificar que las presiones sociales para ser madre se dirigieran a su quehacer académico, salvo en uno de los casos (Selene), por lo que los discursos que son identificados como presión para ser madre en estos cinco casos analizados, son emitidos por su condición de mujer y no como académicas.

En lo que respecta a este trabajo se encuentra al menos una limitación que corresponde al uso de los conceptos. Esto porque a las mujeres entrevistadas se les envió una solicitud que planteaba el tema de la investigación, lo que derivó en juicios previos al encuentro y que sesgaron la información proporcionada, principalmente porque para la recolección de la información se evitó el uso del concepto "presión". Sin embargo, como se señaló en un inicio, esto no impide hacer un análisis teórico de los resultados obtenidos a pesar de ese error.

Otra limitación se encuentra en no haber indagado las demandas para ser madre desde diversos conceptos, ya que la recolección de datos se enfocó en el ámbito familiar, con compañeros de trabajo y otros, pero no se indagó por otros espacios específicos como el consultorio médico ni se amplió la indagación con respecto a los lugares de trabajo. A pesar de ello, como ocurrió con el uso de los conceptos, esto no evitó que al menos el lugar de trabajo fuera señalado, pero no en todas las entrevistas.

En suma, los alcances de la investigación son relevantes ya sea para identificar las experiencias de estas mujeres sin hijos frente a la presión social, para reconocer que es un tema poco abordado y sobre el cual muchas mujeres quieren exponer sus historias, así como para exhibir situaciones que pueden ser mejoradas en futuras investigaciones sobre el tema.

\section{Referencias}

Acker, Sandra. 1995. Género y educación. Madrid: Narcea Ediciones.

Aguinaga, Josune. 2004. El precio de un hijo: los dilemas de la maternidad en una sociedad desigual. Barcelona: Debate.

Ávila, Yanina. 2005. Mujeres frente a los espejos de la maternidad: las que eligen no ser madres. Revista Desacatos, 17: 107-126.

Badinter, Elizabeth. 1981. ¿Existe el amor maternal? Barcelona: Paidós.

Barrón, Sandra. 2004. Ruptura de la conyugalidad e individuación materna: crisis y continuidad. En Las mujeres y los niños primero: discursos de la maternidad, coordinado por Ángeles de la Concha y Raquel Osborne, Barcelona: Icaria, 229-254.

Blackstone, Amy. 2014. Childless or childfree. Contexts, 13 (4): 68-70. https://doi. org/10.1177/1536504214558221 
- Revista de Ciencias Sociales y Humanidades. ISSN-P: 0188-9834 ISSN-E: 2395-8669.

Bosque, Ignacio y Violeta Demonte. 2000. Gramática descriptiva de la lengua española. España: Editorial Espasa.

Casamiglia, Helena y Amparo Tusón. 2001. Las cosas del decir. Barcelona: Editorial Ariel.

Castellanos, Rosario. 1992. La abnegación: una virtud loca. Debate Feminista, 6: 287-292.

Daniluk, Judith. 1996. When biology isn't destiny: the experience of childless women. Vancouver: University of British Columbia.

De Beauvoir, Simone. 1949. El segundo sexo. Madrid: Ediciones Cátedra.

Diccionario de la Lengua Española. http://www.rae.es/ (13 de febrero de 2016).

Díez, Carmen. 2000. Maternidad y orden social. Vivencias de cambio, en Perspectivas feministas desde la antropología social editado por Teresa del Valle Barcelona: Ariel Antropología, 155-186.

Fernández, Iriati. 2014. Feminismo y maternidad: ¿una relación incómoda? España: Emakunde/Instituto Vasco de la Mujer.

Folkman, Susan y Richard Lazarus. 1984. Stress, appraisal and coping. Nueva York: Springer.

Gillespie, Rosemarie. 2000. When no means no: disbelief, disregard and deviance as discourses of voluntary childlessness. Women's studies international forum, 23 (2): 223-234. http://dx.doi.org/10.1016/ S0277-5395(00)00076-5

Gillespie, Rosemarie. 2003. Childfree and feminine. Understanding the gender identity of voluntary childless women. Gender \& Society, 17 (1): 122-136. https://doi.org/10.1177/0891243202238982

Halpern, Diane. 2007. Nurturing careers in psychology: combining work and family. Educational Psychology Review, 20: 57-64. https://doi.org/10.1007/s10648-007-9060-5

Hird, Myra y Kimberly Abshoff. 2000. Women whitout children: a contradiction in terms? Journal of Comparative Family Studies, 31 (3): 347-366.

Lagarde, Marcela. 1996. Género y feminismo. Desarrollo humano y democracia. Madrid: horas y HORAS. Lamas, Marta. 2009. Maternidad voluntaria y aborto. Géneros. Revista de Investigación y divulgación sobre los estudios de género, 2 (6): 122-109.

Lauretis, Teresa. 1986. Feminist studies/critical studies. Indiana: University Press, Bloomington.

Lazarus, Richard. 1999. Estrés y emoción. Manejo e implicaciones en nuestra salud. Bilbao: Desclée De Brouwer.

Letherby, Gayle. 1999. Other than mother and mothers as others: the experience of motherhood and non-motherhood in relation to fertility and involuntary childlessness. Women's Studies International Forum, 22 (3): 359-372. http://dx.doi.org/10.1016/S0277-5395(99)00028-X.

Letherby, Gayle. 2002. Childless and bereft?: stereotypes and realities in relation to "voluntary" and "involuntary" childlessness and womanhood. Sociological inquiry. 72 (1): 7-20. https://doi.org/10.1111/1475$682 X .00003$

Lorber, Judith. 1994. Paradoxes of gender. Nueva York: Yale University

Macías, María, Camilo Madariaga, Marcela Valle, Javier Zambrano. 2013. Estrategias de afrontamiento individual y familiar frente a situaciones de estrés psicológico. Psicología desde el Caribe, 30 (1): 123-145. Mamabolo, Itumeleng, Langa Malose y Kiguwa Peace. 2007. To be or not to be a mother: exploring the notion of motherhood among university students. South Africa Journal of Psychology, 39 (4): 480-488. https://doi.org/10.1177/008124630903900409

Mason, Mary Ann y Marc Goulden. 2002. Do babies matter: the effect on family formation on the life 
- Revista de Ciencias Sociales y Humanidades. ISSN-P: 0188-9834 ISSN-E: 2395-8669.

long careers of academics. Academic Search Premier, 88 (6): 21-28.

Oakley, Ann. 1974. The sociology of housework. Londres: Martin Robertson.

Palomar, Cristina. 2004. "Malas madres": la construcción social de la maternidad. Revista Debate Feminista, 30: 12-34.

Palomar, Cristina. 2005. Maternidad, historia y Cultura. Revista de Estudios de género. La ventana, 22: 35-67.

Royo, Raquel. 2004. Maternidad, paternidad y conciliación en la $C A E_{¿}$ Es el trabajo familiar un trabajo de mujeres? Bilbao: Universidad de Deusto.

Scott, Joan. 2011. Género e historia. México: Fondo de Cultura Económica.

Shaw, Rachel. 2010. Women's experiential Journey toward voluntary and involuntary childlessness: an interpretative phenomenological analysis. Journal of community \& applied social psychology, 21(2): 151163. https://doi.org/10.1002/casp.1072

Tubert, Silvia. 1996. Introducción. En Figuras de la madre, editado por Silvia Tubert Madrid: Ediciones Cátedra, 7-37.

Williams Wendy y Ceci Stephen. 2012. When Scientists choose motherhood, American scientist, 100(2): 138-145. 